\title{
Continuous wavelet transform and Euler deconvolution method and their application to magnetic field data of Jharia coalfield, India
}

\author{
Arvind Singh and Upendra Kumar Singh \\ Department of Applied Geophysics, Indian Institute of Technology (Indian School of Mines), \\ Dhanbad, Jharkhand 826004, India \\ Correspondence to: Arvind Singh (arvindsinghgps@gmail.com)
}

Received: 30 June 2016 - Published in Geosci. Instrum. Method. Data Syst. Discuss.: 23 August 2016

Revised: 19 December 2016 - Accepted: 28 December 2016 - Published: 3 February 2017

\begin{abstract}
This paper deals with the application of continuous wavelet transform (CWT) and Euler deconvolution methods to estimate the source depth using magnetic anomalies. These methods are utilized mainly to focus on the fundamental issue of mapping the major coal seam and locating tectonic lineaments. The main aim of the study is to locate and characterize the source of the magnetic field by transferring the data into an auxiliary space by CWT. The method has been tested on several synthetic source anomalies and finally applied to magnetic field data from Jharia coalfield, India. Using magnetic field data, the mean depth of causative sources points out the different lithospheric depth over the study region. Also, it is inferred that there are two faults, namely the northern boundary fault and the southern boundary fault, which have an orientation in the northeastern and southeastern direction respectively. Moreover, the central part of the region is more faulted and folded than the other parts and has sediment thickness of about $2.4 \mathrm{~km}$. The methods give mean depth of the causative sources without any a priori information, which can be used as an initial model in any inversion algorithm.
\end{abstract}

\section{Introduction}

One of the fundamental issues in exploration geophysics is to detect differences in susceptibility and density between rocks that contain ore deposits, hydrocarbons or coal. These differences are reflected in the gravity and magnetic anomalies and also delineation of structural features, which are interpreted using several techniques (Blakely and Simpson, 1986). One of the most important objectives in the interpretation of po- tential field data is to improve the resolution of the underlying source, delineating a lateral change in magnetic susceptibilities that provides information not only on lithological changes but also on structural trends. The edge detection techniques are used to distinguish between different sizes and different depths of the geological discontinuities (Cooper and Cowan, 2006, 2008; Perez et al., 2005; Ardestani, 2010; Hsu et al., 1996; Hsu, 2002; Holschneider et al., 2003). The derivatives of magnetic data are used to enhance the edges of anomalies and improve significantly the visibility of such features.

Gravity and magnetic signature infer that there is a dominance of sediment over Jharia coalfield (Verma et al., 1973, 1976, 1979). Thus the difference between the depths estimated using the Euler deconvolution method (EDM) (Thompson, 1982; Reid et al., 1990) and tilt depth method (TDM) (Salem et al., 2007; Cooper, 2004, 2011) may help to detect the thickness of the coal bed. Wavelet transform and EDM have been theoretically demonstrated on magnetic data. These methods provide source parameters such as the location, depth, geometry of geological bodies and interfaces in an easy and effective way. However, it may be more difficult to characterize the source properties in cases of extended sources (Sailhac et al., 2009).

Jharia coalfield in Dhanbad, India, forms an east-west trending belt of Gondwana basin, Damodar valley, in the northeastern part of India. This study region is the most coalrich area of Gondwana basin. Analysis of Jharia coalfield suggests that the magnetic anomalies provide encouraging results which are well correlated with available gravity data and some borehole information. 


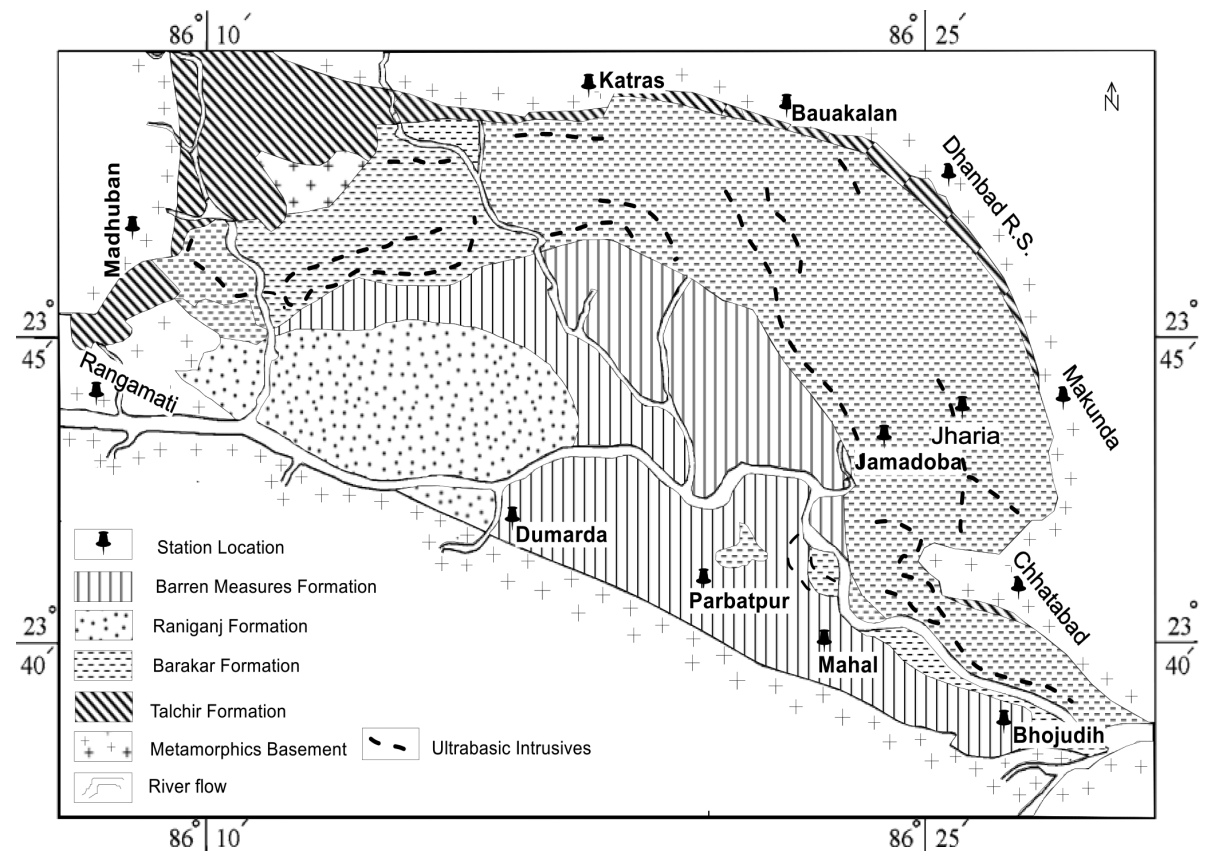

Figure 1. Geological map of Jharia coalfield and surrounding regions (Verma et al., 1979).

\section{Geology of Jharia coalfield}

Geology of the Jharia coal basin is shown in Fig. 1. The basin has been formed because of crustal subsidence during Gondwana periods (Fox, 1930). The coalfield has an extension along the east-west in Gondwana basin of Damodar valley in northeastern India. Gondwana basin is surrounded by crystalline gneisses of several categories from all directions. Sedimentary strata have inclination away from the gneiss contact in this region. The sedimentary strata include the rocks which belong to the Talchir series, Raniganj series, Barren Measures formation and Barakar series (Verma et al., 1979). Raniganj, Barakar and Talchir series, including Barren Measures formation, cover areas of about 58, 218 and $181 \mathrm{~km}^{2}$ respectively. Various formations are shown in the Fig. 1.

Talchir and Barakar formations rest over the northern margin and dip towards the southern margin. The Barakar series covers the northern half of this coalfield. It produces one of the best quality coal in India. An elliptical outline is formed by the Raniganj formation in southwestern region of the coalfield. Geology of the Jharia coalfield has been divided into many blocks, such as the Parbatpur, Mahuda, Jarma and Moonidih blocks. There are many faults over the Jharia coalfield. A normal tensional fault exists over the southern boundary. In the southwestern part of the basin, Damodar river (Fig. 1) flows very close to the southern boundary fault (Verma et al., 1973, 1979; Verma and Ghosh, 1974).

The magnetic data were obtained from Verma et al. (1979) to study the region. We prepared the total magnetic anomaly map of magnetic data of this province as shown in Fig. 2. Magnetic anomaly variations are very smooth over the basin and irregular over Precambrian outcrops. This variation may be affected by the difference in magnetic susceptibility, weathering of the outcrop, magnetization of the outcrop by lightening, etc. At the northern portion of the basin anomalies form a semi-circular arc and are parallel to the southern boundary fault. There is no clear indication of the anomaly at the southern boundary because of uneven basement and faulting associated with Patherdih horst. So it is clear that this portion of the basin is highly folded/faulted and coal seams have been highly deformed. A noticeable part of the magnetic anomaly is the presence of major anomalous sources which are ascribed to some features within the Precambrian basement's underlying sediments.

\section{Methodologies}

\subsection{Continuous wavelet transform (CWT)}

The continuous wavelet transform is the conversion of any signal into a matrix made of sum scaler products in Fourier space. Wavelet transform method for potential field has been established by Moreau et al. (1997, 1999). This method was previously used for homogeneous, isolated and extended potential field sources (Sailhac et al., 2009). Chamoli et al. (2006), Cooper (2006), Goyal and Tiwari (2014) and Singh and Singh (2015) used wavelet transform method on various synthetic as well as field data. This method uses a Poisson group of wavelets as a mother wavelet in order to interpret the potential field data. To analyze the signal by mother wavelet, a wavelet domain signal is decomposed into the orthogonal wavelets of finite duration. The CWT coeffi- 


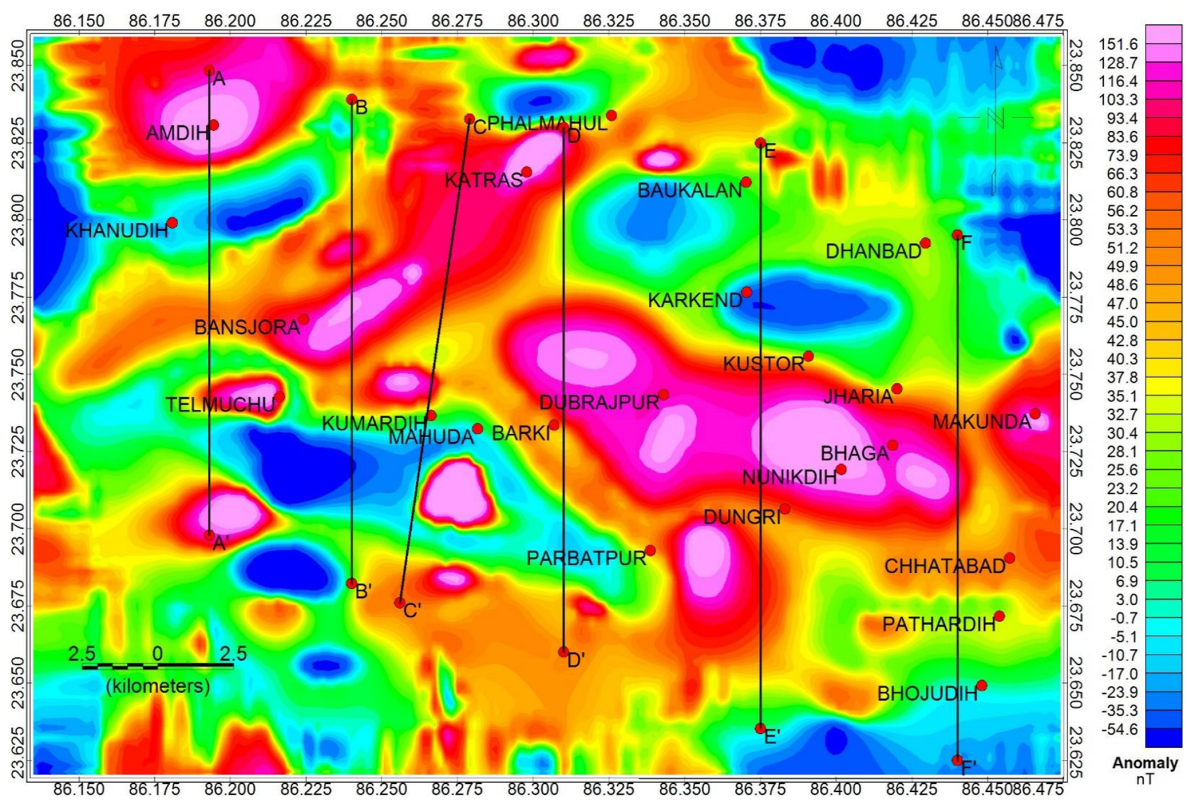

Figure 2. Total magnetic field anomaly (nT) map and location of the profiles over Jharia coalfield and surrounding regions (Verma et al., 1979).

cient $W_{t}$ of a measured potential $t(x)$ is defined as the convolution product.

$$
\begin{aligned}
W[\psi, t](p, o) & =\int_{R^{n}} \frac{1}{o^{n}} t(x) \psi\left[\frac{p-x}{o}\right] \mathrm{d} x, \\
W[\psi, t](p, o) & =\left(D_{\mathrm{o}} \psi * t\right)(p),
\end{aligned}
$$

where $\psi\left(x \in R^{n}\right)$ is the wavelet to be analyzed, $x$ denotes the abscissa along the particular profile line, $t(x)$ indicates the potential field (gravity or magnetic anomaly) and $\left(o \in R^{+}\right)$ and $p$ are the dilation and position parameter respectively. Dilation parameter allows the analyzed wavelet to act as a band pass filter. Dilation operator $D_{\mathrm{o}}$ can be termed as

$D_{\mathrm{o}} \psi(x)=\frac{1}{o^{n}} \psi\left(\frac{x}{o}\right)$

Dilation $D_{\mathrm{o}}$ fulfils two properties given below.

$W\left[\psi, D_{\lambda} t\right](p, o)=\frac{1}{\lambda^{n}} W[\psi, t]\left(\frac{p}{\lambda}, \frac{o}{\lambda}\right)$

Equation 4 states one of the main mathematical asset of the wavelet transform, i.e., covariance of wavelet transforms with respect to the dilation. The homogeneous function $t$ of degree $\sigma \in R$ can be defined as

$t(\lambda, x)=\lambda^{\sigma} t(x) \forall \lambda>0$.

After correlation, Eqs. (4) and (5) result in the homogeneous function (i.e., by recalling $\sigma=-n$ and $\sigma=0$ respectively)

$(\lambda p, \lambda o) W[\psi, t]=\lambda^{\sigma} W[\psi, t](p, o)$.
Equation (6) shows that wavelet transform of a homogeneous function is analogous to dilation and scale of any function $W(\psi, t)(p, o=$ consant $)$ of the wavelet transform. Moreau et al. (1999) suggest that the combinations of straight lines create a cone-like outline at the location where $\left(\frac{\partial^{m}}{\partial p^{m}}\right) W(\psi, t)(p, o)=0$ and the apex of the outline is the center of homogeneity of the analyzed function. The outlines in Fig. 3 fulfils the condition $\left(\frac{\partial^{m}}{\partial p^{m}}\right) W(\psi, t)(p, o)=0$ and are known as edges of wavelet transform or modulus maxima lines.

Potential field signal analyzed by CWT allows for estimation of depth and homogeneous distribution order of the source generating the analyzed signal. Source depth is calculated through the intersection of the converging extrema lines (Fig. 3). In addition to this, Moreau et al. $(1997,1999)$ established the Poisson semi-group kernel $K_{\mathrm{o}}(x)$ that allows us to carry on the harmonic field $t(x, z)$ from level $z$ to the level $z+o$, which is expressed as upward continuation (Bhattacharyya, 1972).

$P_{\mathrm{o}}(x)=\frac{o}{\pi}\left(\frac{1}{o^{2}+x^{2}}\right)$

For wavelet analysis, let us consider a local homogeneous source $x=0$, with depth $z=z_{\alpha}$, of a potential field $t(x, z=$ $0)$. Moreau (1999) stated that the wavelet coefficients of positions and dilations that lie in the upper half plane follow a twice scaling rule with two exponent parameters. Moreau (1997) explained the relationship between wavelet coefficients at two altitudes and for any wavelets of homoge- 


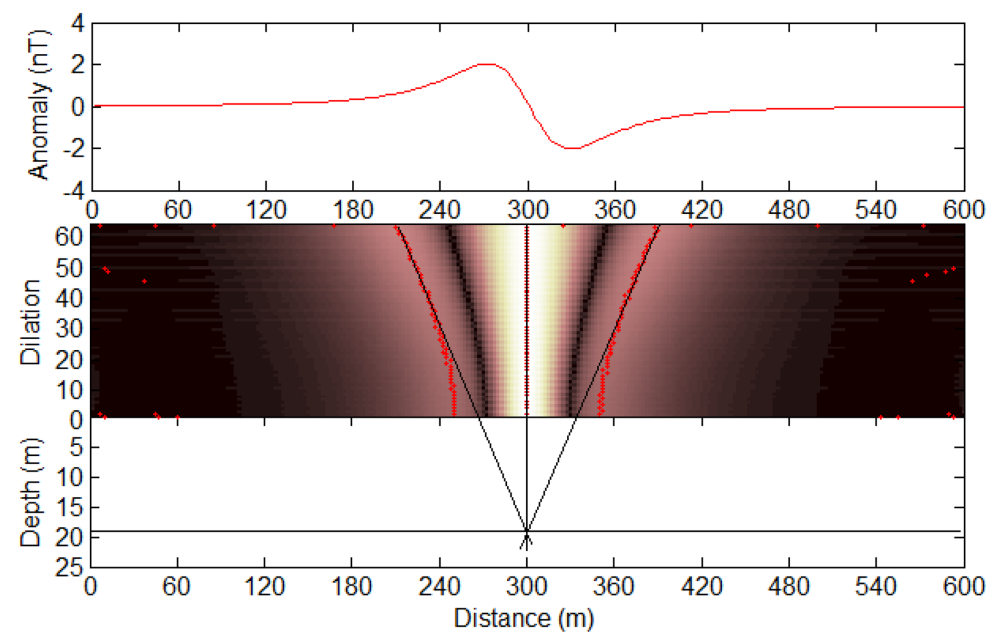

Figure 3. Synthetic magnetic anomaly of isolated extended source and depth estimation by wavelet transform for a Poisson wavelet for $\gamma=1$ with mathematical expression $k(x)=-[x(2 / \pi)] /\left(1+x^{2}\right)^{2}$.

neous sources as

$W[\psi, t](p, o)=\left(\frac{o}{o^{\prime}}\right)^{\gamma}\left(\frac{o^{\prime}+z_{\alpha}}{o+z_{\alpha}}\right)^{\beta} W\left(p \frac{o^{\prime}+z_{\alpha}}{o+z_{\alpha}}, o^{\prime}\right)$,

where $\beta=\gamma-\sigma-2$ indicates the holder exponent, $o$ and $o^{\prime}$ denote different altitudes and $Z_{\alpha}$ signifies the depth of the causative source. Equations (6) is similar to Eq. (8), with the additional term $Z_{\alpha}$ in both the dilation and scaling factors on the right-hand side resulting in geometrical conversion. Due to geometrical conversion the cone-like outline joins at source depth because of the negative dilation $o=z_{\alpha}$. Therefore, the Poisson group of wavelets used on the potential field demonstrates modest assets and can be applied to find the causative source without any prior information. CWT helps to detect the edge of the formations of the extended body. Also, it offers quick and consistent results about extended and isolated source depth with location. Wavelet analysis plays a key role in depth estimation of potential field. When order of $\gamma$ increases, the obtained source depth appears shallower. For $\gamma=1$, outlines of the cone have the point of intersection at the barycenter of the prismatic source. CWT can resolve the noisy and nonstationary dataset very well (Moreau, 1997, 1999) and magnetic data can also be analyzed without any reduction to pole.

\subsection{Euler deconvolution method}

Euler deconvolution was first developed for the interpretation of magnetic profile data by Thompson (1982), and later Reid et al. (1990) extended its approach to gridded magnetic data. Reid et al. (1990) developed the special case for the magnetic field of a contact of finite depth extent and coined the term "Euler deconvolution". Klingele et al. (1991) and Zhang et al. (2000) used it over vertical gravity gradient and tenser gravity gradient respectively. Moreover, it has been generalized by Mushayandebvu et al. (2001, 2004), and Ravat (1996) further investigated the wider range of source nature by this method. Since then, it has been adapted and improved by Keating (1998) to interpret the gravity data. EDM makes rapid depth estimations from magnetic and gravity data in grid form using Euler's homogeneity relation (Thompson, 1982; Reid et al., 1990; Barbosa et al., 1999). Euler deconvolution is insensitive to magnetic inclination, declination and remanent magnetization and is very suitable for 3-D analyses (Keating, 1998; Mushayandebvu et al., 2004; Stavrev and Reid, 2007; Melo et al., 2013, Silva, et al., 2001).

The global acceptance of Euler deconvolution is mainly due to its simplicity of implementation and use, making it the tool of choice for a quick and reliable interpretation of potential field data (FitzGerald et al., 2004; Gerovska and Arauzo Bravo, 2003) and for finding the source information in terms of depth and geological structure. Euler deconvolution uses three orthogonal gradients of any potential quantity as well as the potential quantity itself to determine depths and locations of a source body. This method primarily responds to the gradients in the data and effectively traces the edge and defines the depth of the source body. Reid et al. (1990) and Thompson (1982) defined the 3-D Euler equation as

$\left(x-x_{0}\right) \frac{\mathrm{d} \boldsymbol{F}}{\mathrm{d} x}+\left(y-y_{0}\right) \frac{\mathrm{d} \boldsymbol{F}}{\mathrm{d} y}+\left(z-z_{0}\right) \frac{\mathrm{d} \boldsymbol{F}}{\mathrm{d} z}+N \boldsymbol{F}=0$,

where $\left(x_{0}, y_{0}, z_{0}\right)$ is the location of magnetic source whose total magnetic field $(\boldsymbol{F})$ is observed at $(x, y, z)$. The values $\frac{\mathrm{d} \boldsymbol{F}}{\mathrm{d} x}, \frac{\mathrm{d} \boldsymbol{F}}{\mathrm{d} y}$ and $\frac{\mathrm{d} T}{\mathrm{~d} z}$ are the measured magnetic gradients along the $x, y$ and $z$ directions. Euler deconvolution adds an extra dimension to the interpretation. It estimates a set of $(x, y, z)$ points that, ideally, fall inside the source of the anomaly. Euler deconvolution requires the $x, y$ and $z$ derivatives of the data and a parameter called the structural index (SI), $N(N$ 
is a nonnegative integer). SI defines the anomaly attenuation rate at the observation point and depends on the geometry of the source. The SI is an integer number that is related to the homogeneity of the potential field and varies for different fields and source types (Stavrev and Reid, 2007; Barbosa et al., 1999; and Melo et al., 2013). For example, in the case of total field magnetic anomaly data, a dyke is represented by an SI of 1, whereas a sphere is represented by an SI of 3 .

The source points that are calculated as solutions by EDM are positioned at the estimated edge of the susceptibility inhomogeneities. Thus, the EDM relies on the derivatives of the magnetic data; the resulting depth estimates relate mainly to the areas of basement heterogeneities identified as distinct sources of the field. The first vertical gradient of magnetic data is calculated by using the fast Fourier transform (FFT) method (Gunn, 1975). The vertical and horizontal derivatives of the first vertical gradient, essential for the calculation of Eq. (9), are also been calculated using the FFT method. The horizontal source locations from EDM solutions can be used to explain of lithological and structural trends. A location in the map where these solutions tend to cluster is considered to be the most probable location of the source.

Equation (9) can be explained in terms of least squares to estimate the source coordinates and structure. Since the absolute value anomalous field $(\boldsymbol{F})$ is barely identified, Eq. (9) cannot be used directly over the observed data. Moreover, according to Thompson (1982) Eq. (9) does not explain the regional or background magnetic field due to adjacent source, so obtained solutions may be unreliable and may vary from their accurate location.

For the 2-D model, total magnetic field $(\boldsymbol{F})$ and its derivatives at all points of observations provide the linear equation with unknown coordinates $\left(x_{0}\right.$ and $\left.z_{0}\right)$, where $x_{0}$ and $z_{0}$ represent location and depth of the magnetic source, respectively.

Using the Taylor series, an unidentified regional field $(\boldsymbol{E})$ can be described as

$\boldsymbol{E}(x, y)=\boldsymbol{E}_{0}+x \frac{\partial \boldsymbol{E}}{\partial x}+y \frac{\partial \boldsymbol{E}}{\partial y}+K(2)$,

where $\boldsymbol{E}_{0}$ and $K(2)$ represent the constant background for definite window and other higher-order values in Taylor series expansion. The resultant anomalous field $(\boldsymbol{F})$ can now be specified as the difference between the observed magnetic field $(\boldsymbol{O})$ and regional magnetic field $(\boldsymbol{E})$.

$\boldsymbol{F}=\boldsymbol{O}-\boldsymbol{E}$
Now, after revision, modified Euler equation can be specified as

$$
\begin{aligned}
\boldsymbol{O} \equiv & \left(x-x_{0}\right) \frac{d(\boldsymbol{O}-\boldsymbol{E})}{\mathrm{d} x}+\left(y-y_{0}\right) \frac{d(\boldsymbol{O}-\boldsymbol{E})}{\mathrm{d} y} \\
& +\left(z-z_{0}\right) \frac{\mathrm{d}(\boldsymbol{O}-\boldsymbol{E})}{\mathrm{d} z}+N(\boldsymbol{O}-\boldsymbol{E})=0 .
\end{aligned}
$$

According to Thompson (1982), Silva and Barbosa (2003) and Reid et al. (1990), Euler equation provides satisfactory results by considering the first-order term in Taylor series expansion. Also, the Euler equation becomes nonlinear and is resolved linearly by supposing tentative values of the SI (Stavrev, 1997). The higher-order term of Taylor series expansion provides the solution when singular points are closely spaced to each other (e.g., in the case of the multiple fracture or sill). In this case postulation of linear background discontinues and needs higher-order terms of Taylor series expansion for a reasonable result.

Dewangan et al. (2007) and Gerovska and Arauzo Bravo (2003) chose the second-order terms of the Taylor series expansion and favor a procedure of rational calculation in which the infinite Taylor series expansion is estimated by two polynomials (one lies in the numerator and other one in the denominator). Kopal (1961) suggested that the maximum accuracy in rational calculation may be possible when the polynomials of the numerator and denominator hold the same power. The rational function is used to calculate the background; this function can be defined as

$\boldsymbol{E}(x, y)=\left(\frac{\boldsymbol{E}_{0}+a x+b y}{1+c y+\mathrm{d} y}\right)$,

where $a, b, c, d$ and $\boldsymbol{E}_{0}$ are the unknown parameters. Comparison of the values of Eqs. (13) and (12) generates another nonlinear Euler equation which provides the source depth, location and structural index (Coleman and Li, 1996; Williams et al., 2003). All the variation on Euler deconvolution includes working through profiles as well as gridded datasets using a moving window (each window position is a set of linear equations which generate the solution to locate the source in plan and depth). The advantage of this method is that source magnetization direction and its result are not affected by the presence of remanence (Ravat, 1996). Moreover, it can be further used as an inversion algorithm and the design rules based on mathematical analysis proposed by Reid et al. (2014) must be considered to analyze the potential field (gravity and magnetics).

\section{Application of CWT to synthetic magnetic anomaly}

The synthetic examples demonstrate the application of the CWT technique on the magnetic anomaly due to isolated and extended homogeneous magnetic sources at $300 \mathrm{~m}$, with depth about $20 \mathrm{~m}$. The first analysis (shown in Fig. 3) corresponds to the magnetic anomaly of a finite length vertical 
(a)

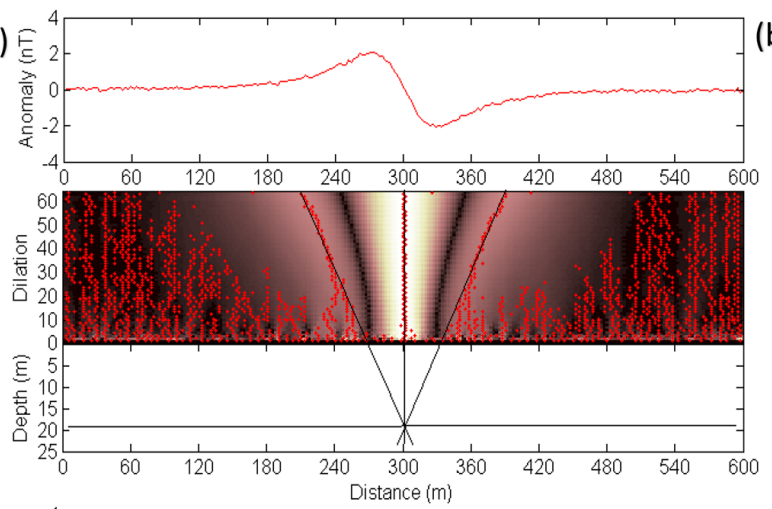

(c)
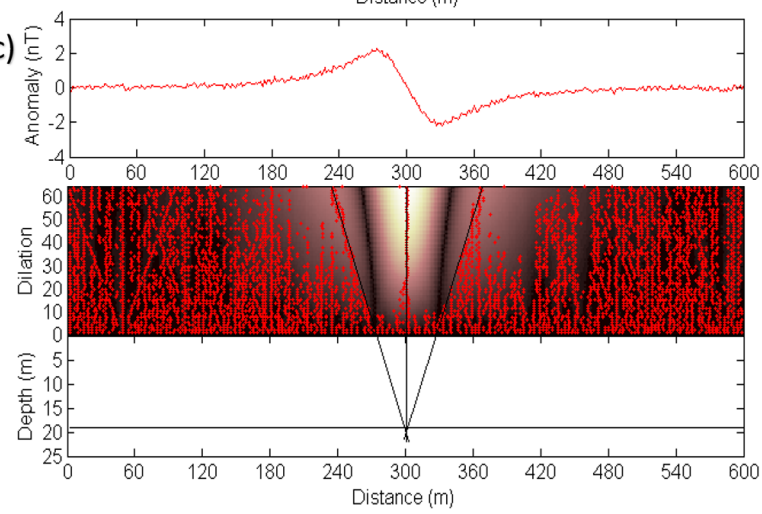

(b)

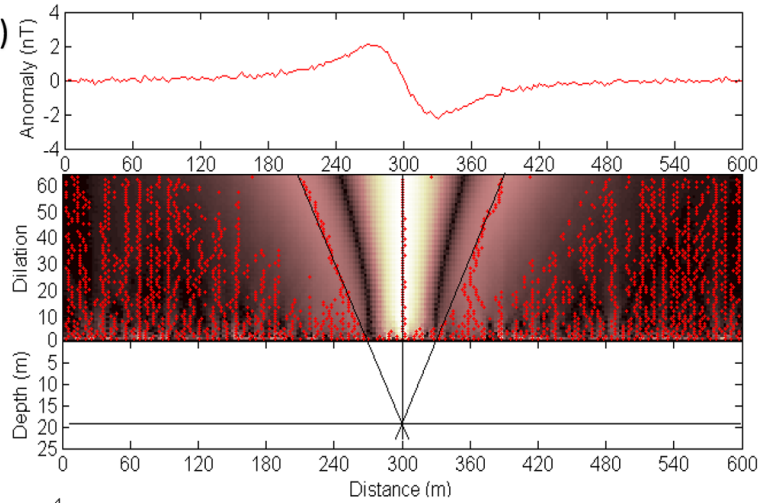

(d)
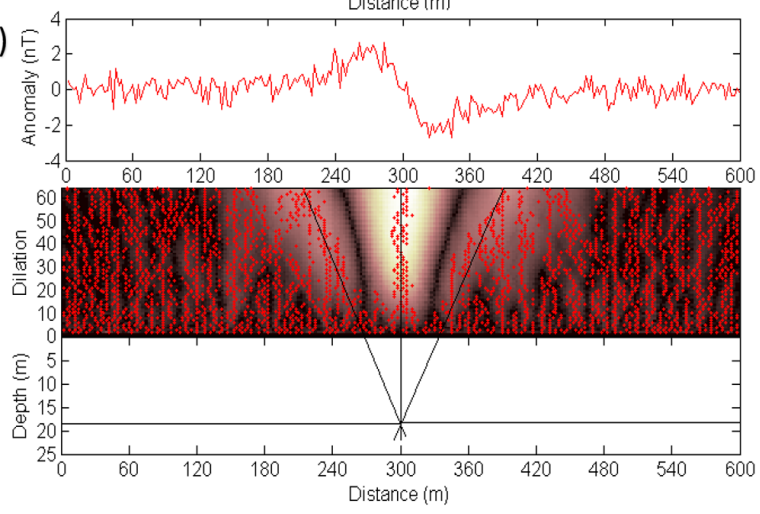

Figure 4. (a) Magnetic anomaly with $1 \%$ random noise; (b) magnetic anomaly with $2 \%$ random noise; (c) magnetic anomaly with $5 \%$ random noise; (d) magnetic anomaly with $10 \%$ random noise.

dipole. The wavelet coefficients of the magnetic field due to vertical dipole computed with the help of wavelet are shown in this figure (for horizontal derivative $\gamma=1$ ), which shows a cone-like structure. Wavelet transform of the potential field due to homogeneous source follows a geometrical property which allows an easy estimation of source depth and location. The examples demonstrated could correspond to the zero remanent magnetization with all magnetization being induced. To understand the behavior of the modulus maxima of CWT over the magnetic anomaly due to the anomalous sources, the CWT is presented for various field examples. The converging point of ridges gives depth and location of the vertical dipole.

The wavelet coefficients are computed by applying CWT to the anomaly. Figure 4 shows the calculated values of CWT coefficients for different dilations (1-64.5) of magnetic anomaly. The maxima of modulus of CWT provide cone-like structures and are clearly shown pointing towards the position of the upper corner of the model. Whereas an approximate horizontal location has been estimated, an intersection of modulus maxima lines in the subsurface has been placed below the base line $(a=0)$ to mark the depth of the source, where $a$ is dilation.

Also, this example illustrates the application of wavelet transform to potential fields (horizontal derivative, $\gamma=1$ ) where modulus maxima lines make a cone-like shape, and ridges of the cone join below the base line or to homogeneity center of the source, where $y$ scale represents the dilation. The point where ridges join marks the depth and location of the vertical dipole. It is detected that the homogeneous source retains a geometrical possession after execution of wavelet transform on potential field. This makes a straightforward interpretation about depth and location of causative body. In order to perform wavelet analysis on field data, it has been tested on noisy data with $1,2,5$ and $10 \%$ random noise in the potential source data obtained because of vertical dipole (Fig. 4a-d). It is clear that wavelet analysis provides the exact depth and location of the source. When the noise level is low then it is easy to find the cone-like structure where the modulus maxima lines cross each other (Fig. 4a-b). As the noise level increases it is difficult to find the cone-like structure made by the cross section of modulus maxima line (Fig. 4c-d).

\section{Application of CWT to magnetic field anomaly from Jharia coalfield}

CWT and EDM are applied on field magnetic anomaly collected from Jharia coalfield and surrounding regions in Dhanbad, India. For CWT analysis, six profiles $\left(\mathrm{AA}^{\prime}, \mathrm{BB}^{\prime}, \mathrm{CC}^{\prime}\right.$, $\mathrm{DD}^{\prime}, \mathrm{EE}^{\prime}$ and $\mathrm{FF}^{\prime}$ ) have been selected that cover the entire coalfield. These anomalies can be adequately explained 
by assuming an underlying body with susceptibility contrast with respect to its surroundings and which is polarized in $\mathrm{N}-$ $\mathrm{S}$ direction. The positive anomaly in the northern part of the basin is clearly seen in the profile.

The remanent magnetization of the body also appears to contribute to the anomaly. It is interesting to note that in the region of this magnetic anomaly a number of dykes and sills are found as intrusive into the sediments as shown in Fig. 1. This anomaly therefore could be ascribed to the presence of a basic or ultrabasic body which could be the source for the basic dykes and sills which intruded into the basin during Gondwana times. Alternatively, this anomaly could also represent a basic intrusive of Precambrian age underlying the sediments. There are practically no basic intrusives present in the region of positive anomaly. Therefore, this anomaly could be more definitely ascribed to an intrusive body of Precambrian age (Verma et al., 1979).

\section{Results and discussion}

In order to check the reliability of the interpreted results obtained from Euler deconvolution, CWT and geological sections, construction information was collected from published results of boreholes drilled by Geological Society of India (GSI), Bharat Coking Coal Limited (BCCL), National Coal Development Corporation (NCDC) and Central Mines Planning and Design Institute (CMPDI). Therefore, the depth to the basement configuration inferred from gravity data as well as drilled borehole information is discussed below.

Jharia coalfield and surrounding areas have been considered to estimate the source depths on the basis of technique of intersections of modulus maxima lines of CWT. The mean depths of causative sources along the profile $\mathrm{AA}^{\prime}$ (passes east of the Khanudih and west of the Telmuchu and Bansjora region through Amdih over the westernmost part of the Jharia coalfield, shown in Fig. 2) calculated from the CWT (Fig. 5a) and Daubechies' wavelet method (Fig. 5b) vary from 0.2 to $0.45 \mathrm{~km}$. Profile $\mathrm{AA}^{\prime}$ shows that there is fault near the northwestern part of the basin.

Magnetic field inclination, declination and azimuth angle (clockwise from true north) of this profile are $36.44,-0.11$ and $268.48^{\circ}$ respectively. The anomaly about $77 \mathrm{nT}$ between boreholes JM-4 and JK-26 has been observed because of a number of basic intrusive bodies belonging to Satpura cycle that exist over the area. Jharia coalfield consists of peridotites in the form of sills as well as dykes. Dolerite dykes are very common in the western part of this coalfield.

The central part shows a flat sedimentary region and the magnetic anomaly shows a high value on either side of the profile. Raniganj formation exists on the southern side whereas Talchir formation exists on the northern side of this profile. However, the Barren Measures and the Barakar formation lie between the Raniganj and the Talchir formations. There is an intrusion of Archean metamorphics in Talchir formation which appears as an outcrop over the surface near
Amdih (Fig. 5c). Some of the boreholes provide information about the metamorphics along this profile. The maximum thickness of the sediment along this profile is observed to be about $0.8 \mathrm{~km}$.

Boreholes JM-1, JM-4 and JK-26 are located close to this profile, which touches metamorphics at a depth of about 0.4 , 0.55 and $0.3 \mathrm{~km}$ respectively. These boreholes are located west of Bansjora and Telmuchu. The depth to the basement obtained from magnetic data is nearly equal to the depth obtained from gravity data along these profiles (Singh and Singh, 2015).

The mean depths of causative sources along the profile $\mathrm{BB}^{\prime}$ (passes east of Telmuchu and Bansjora and west of $\mathrm{Ku}-$ mardih region, shown in Fig. 2) calculated from the CWT (Fig. 6a) and Daubechies' wavelet (Fig. 6b) vary from 1.3 to $2.5 \mathrm{~km}$. The central part of the basin shows the abrupt changes in the magnetic anomaly.

Profile BB' illustrates about the Barakar, Raniganj, Talchir formations and Barren Measures. The Barren Measures is found between the Barakar and Raniganj formations and seen as an outcrop in both sides of the Raniganj formation. Also, an intrusion of the Talchir formation has been found in Archean metamorphics and an intrustion of the Barakar formation at the northern end of the profile (Fig. 6c). There is a sloppy nature of each formation below the profile from both ends. The major portion of this area is dominated by the Raniganj and the Barakar formations. The estimated thickness of the sediments is about $2.3 \mathrm{~km}$ over the Raniganj formation.

Magnetic field inclination, declination and azimuth angle of this profile are $36.42,-0.11$ and $268.5^{\circ}$ respectively. This profile passes through two faults between metamorphics and sediment: one is at the southern end while the other is at the northern end of the profile. Faults are indicated by steep gradient of magnetic anomaly. The magnetic anomaly of about 103 and 162 nT southeast and east of Bansjora, respectively, represents the occurrence of Precambrian basement underlying the sediments.

The boreholes JK-7 and JM-8 are located near this profile. From borehole JM-7, it is obtained that maximum thickness of the Raniganj formation is about $0.22 \mathrm{~km}$ and Barren Measures lies below it. It touches the Barakar formation at a depth of about $1.2 \mathrm{~km}$, east of Bansjora. From the obtained results from borehole $\mathrm{JK}-8$, it is clear that sediment thickness is about $0.3 \mathrm{~km}$ and the borehole touches the Barren Measures at a depth of about $300 \mathrm{~m}$.

The mean depths of causative sources along the profile $\mathrm{CC}^{\prime}$ (passes west of Mahuda and Katras through Kumardih region, shown in Fig. 2) calculated from the CWT (Fig. 7b) and Daubechies' wavelet method (Fig. 7b) vary from 1 to $2 \mathrm{~km}$. The northern part of the basin shows the flatness in the basin. Most of the sedimentary formations exist along the profile $\mathrm{CC}^{\prime}$. Figure $7 \mathrm{c}$ reveals that there is a strong indication that both boundaries slope towards the central part of 

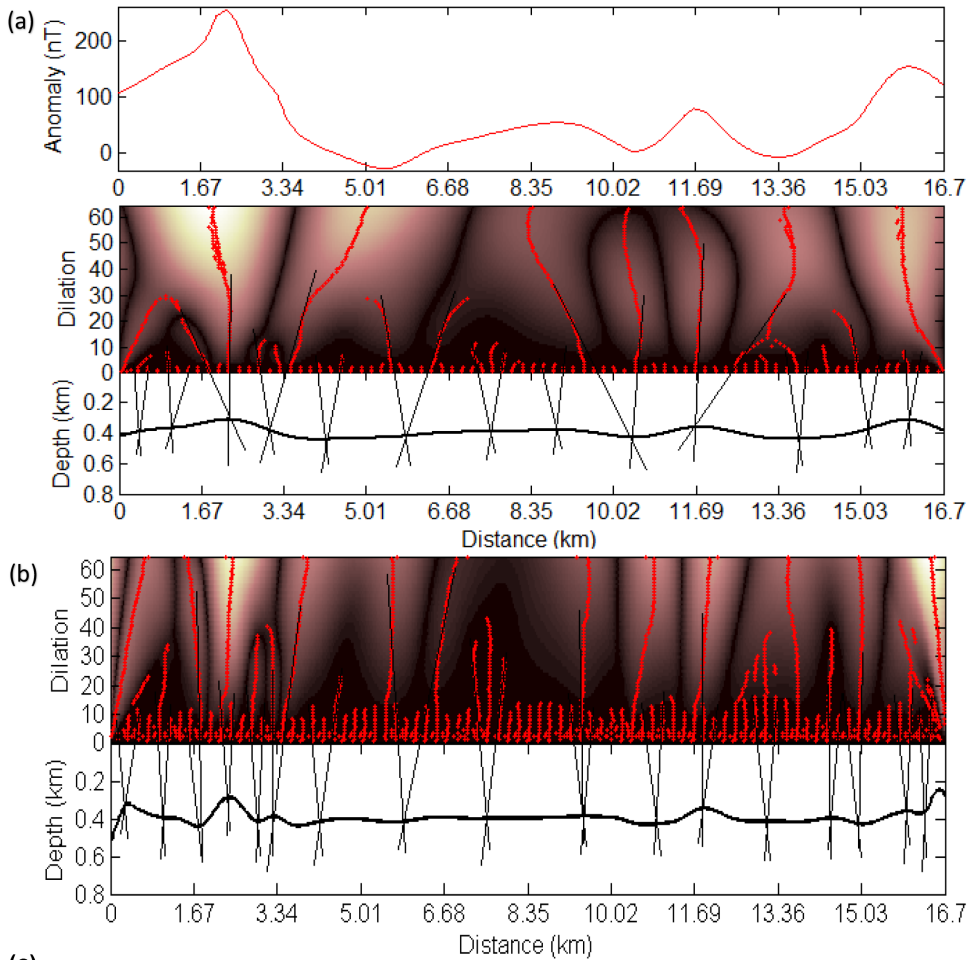

(c)

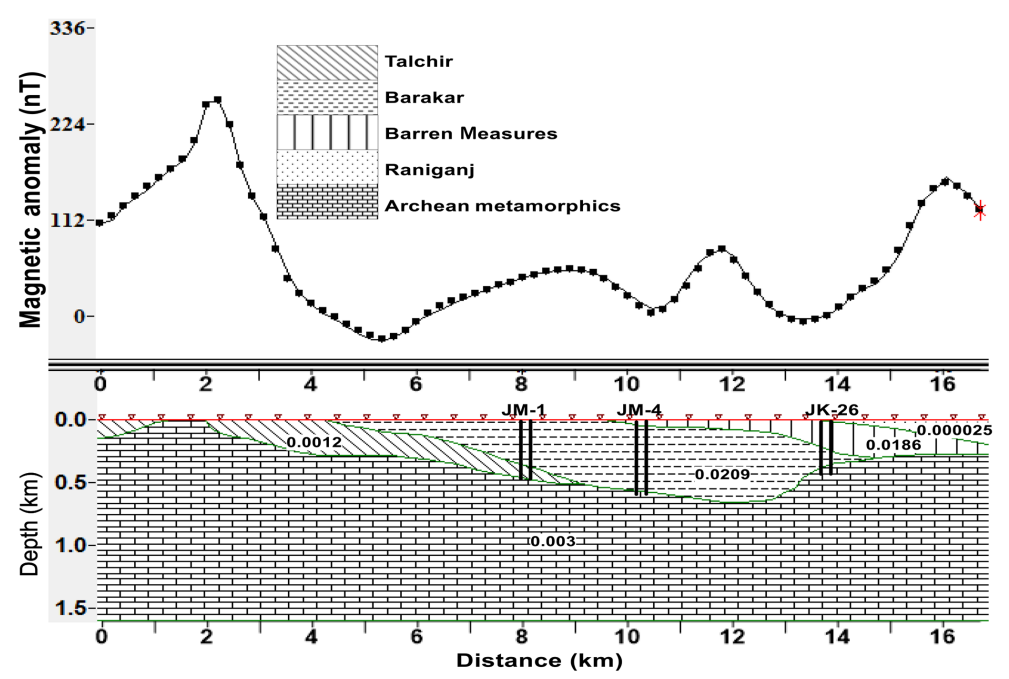

Figure 5. (a) Magnetic anomaly across the profile $\mathrm{AA}^{\prime}$ (drawn in Fig. 2) and depth estimation by continuous wavelet transform. (b) Depth estimation by Daubechies' wavelet method. (c) Geological section of the profile $\mathrm{AA}^{\prime}$ along with boreholes and magnetic susceptibility (shown in Table 2) of related formation.

the basin and the southern boundary is categorized by a more abrupt slope than the northern.

Magnetic field inclination, declination and azimuth angle of this profile are $36.41,-0.12$ and $268.516^{\circ}$ respectively. Gee (1932) mentioned four dykes in the memoir of this coalfield, namely Salama dyke, Sitarampur dyke, Charanpur dyke and Barakar river dyke. The flow of the Barakar river is shown in Fig. 1. It is remarkable that in the region of this magnetic anomaly profile numbers of ultrabasic dyke (mica peridotites) and sills are found as intrusive into sediments and Barakar formation causes magnetization of the body in the present earth's field.

Similar to profile $\mathrm{BB}^{\prime}$, Barren Measures lies between the Raniganj and Barakar formations. Also, the Talchir formation lies between the Barakar and Archean metamorphics whose thickness varies from about 1.8 to $2.2 \mathrm{~km}$ at the northcentral part of the basin. The thickness of sediments near Kumardih and Mahuda is about $2.4 \mathrm{~km}$. Moreover, geological 

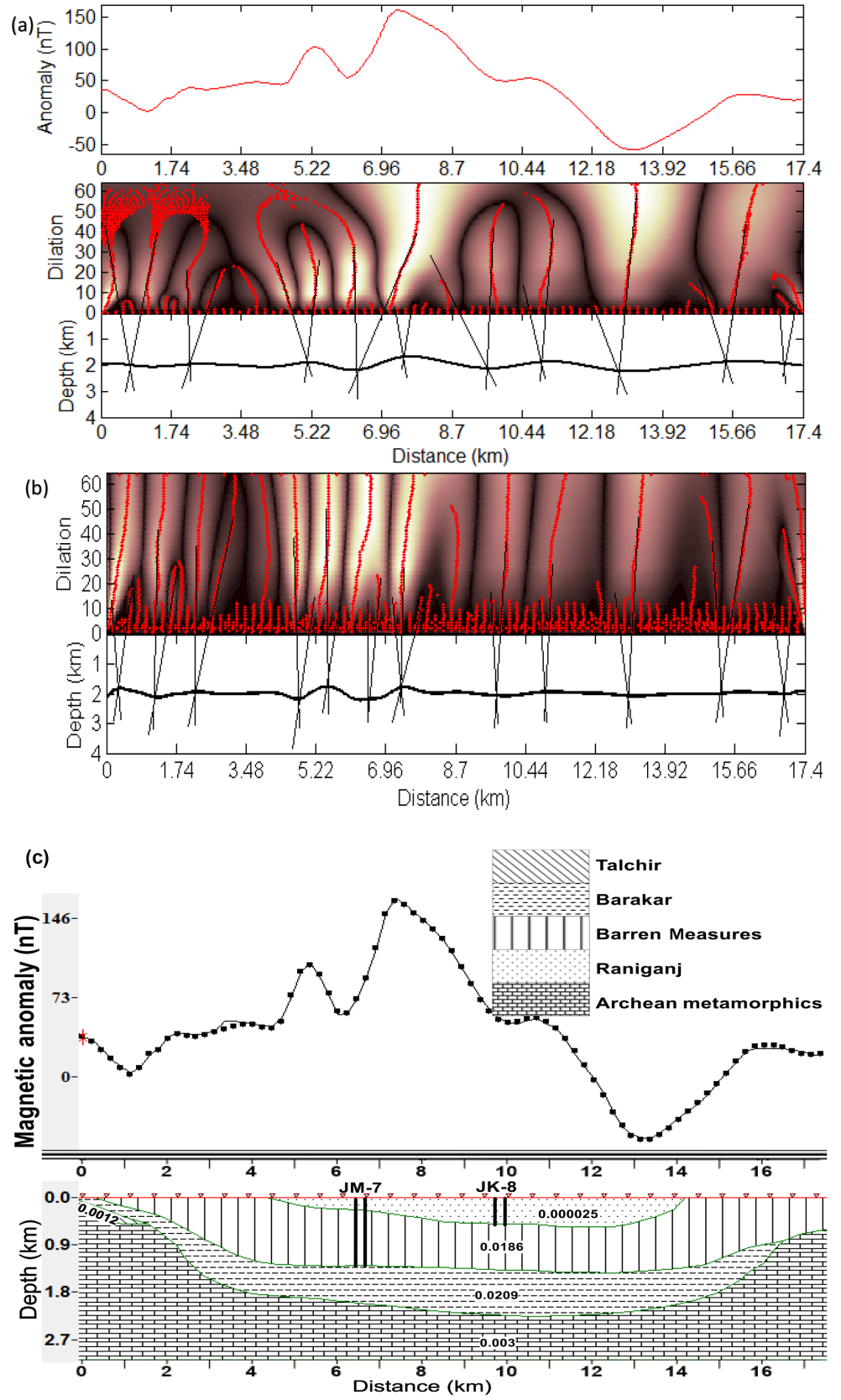

Figure 6. (a) Magnetic anomaly across the profile $\mathrm{BB}^{\prime}$ and depth estimation by continuous wavelet transform. (b) Depth estimation by Daubechies' wavelet. (c) Geological section of the profile BB' along with boreholes and magnetic susceptibility (shown in Table 2) of related formation.

sections along the profile $\mathrm{CC}^{\prime}$ are also based on the results obtained from gravity data (Singh and Singh, 2015), borehole information as well as geological information. Boreholes NCJA-4, NCJA-5 and MN-11 are located near this profile. Boreholes NCJA-4 and NCJA-5 are located southwest of Katras and northeast of Kumardih. Depths of individual formations near the deepest part of the basin are about $0.4 \mathrm{~km}$ for Raniganj formation, $0.95 \mathrm{~km}$ for Barren Measures, $0.8 \mathrm{~km}$ for Barakar formation and $0.2 \mathrm{~km}$ for Talchir formation.
The mean depths of causative sources along the profile DD' (passes east of Mahuda and Katras and west of Parbatpur and Dubrajpur through Barki region, shown in Fig. 2) calculated from the CWT (Fig. 8a) and Daubechies' wavelet method (Fig. $8 \mathrm{~b}$ ) vary from 1 to $2.4 \mathrm{~km}$. Also, along this profile there are some indications of fractious contact between the Barakar formation and Barren Measures. The Barakar formation appears to pinch out close to the southern boundary fault. 

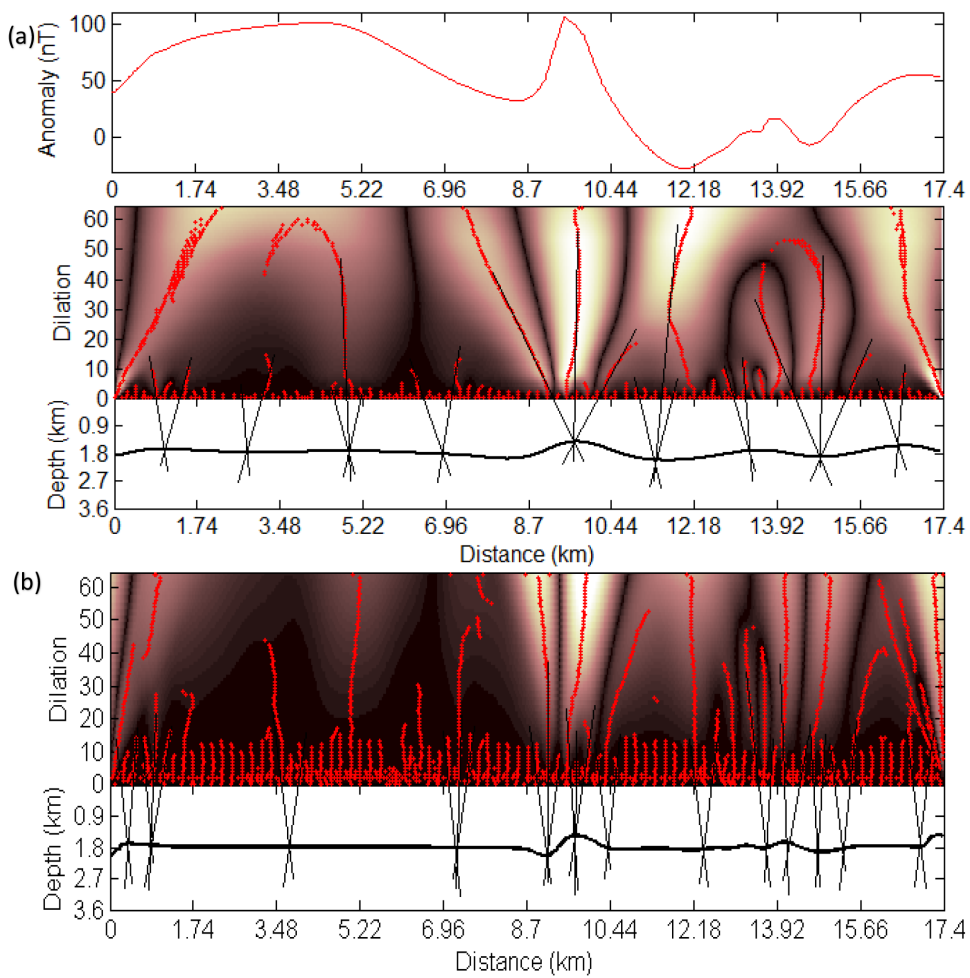

(c)
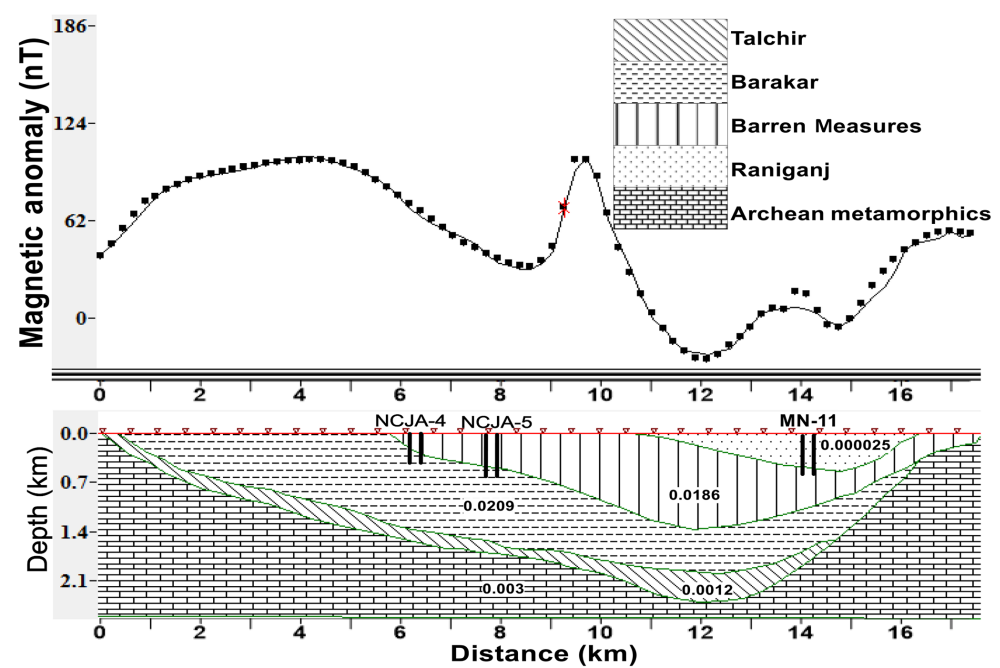

Figure 7. (a) Magnetic anomaly across the profile $\mathrm{CC}^{\prime}$ (drawn in Fig. 2) and depth estimation by continuous wavelet transform. (b) Depth estimation by Daubechies' wavelet. (c) Geological section of the profile $\mathrm{CC}^{\prime}$ along with boreholes and magnetic susceptibility (shown in Table 2) of related formation.

Magnetic field inclination, declination and azimuth angle of this profile are $36.40,-0.12$ and $268.529^{\circ}$ respectively. Faults between Barakar formation and metamorphics are clearly indicated by steep gradients of magnetic anomaly at the northern end of the profile. The southern end of the profile is characterized by magnetic variation that appears to be due to an uneven topography. The middle of the profile is characterized by a magnetic high of about $151 \mathrm{nT}$ because of 2-D linear features and a magnetic pole which lies nearly
$0.5-0.65 \mathrm{~km}$ below the surface in this region. The extent of the Talchir formation assumed to be underlying the Barakar formation is uncertain. Some coal seams exhibited on the surface and northern side have a steeper dip than the southern side. Approximate depth of the basement in this area estimated from a single pole was $2 \mathrm{~km}$ (Fig. 8c) below the surface, southwest of Parbatpur.

Geological sections along this profile were also deduced from the analysis of borehole information, gravity data 

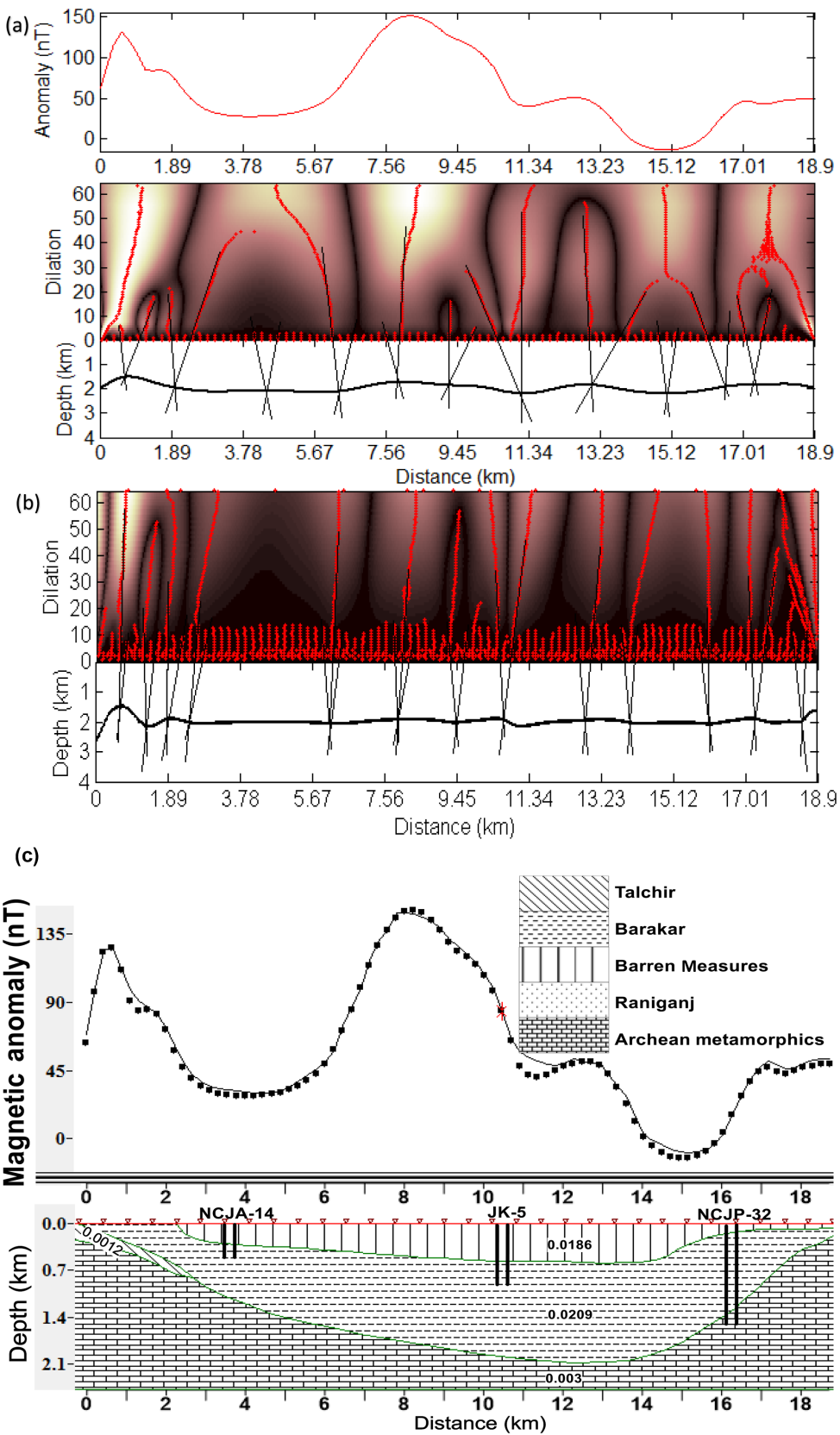

Figure 8. (a) Magnetic anomaly across the profile DD' (drawn in Fig. 2) and depth estimation by continuous wavelet transform. (b) Depth estimation by Daubechies' wavelet. (c) Geological section of the profile DD' along with boreholes and magnetic susceptibility (shown in Table 2) of related formation.

and geological information. Boreholes NCJA-14, JK-5 and NCJP-32 are located east of Katras, north west of Dubrajpur and west of Parbatpur respectively. The individual maximum thickness of various formations near the deepest part of the basin is about $0.8 \mathrm{~km}$ for Talchir, $0.4 \mathrm{~km}$ for Barren Measures and about $2 \mathrm{~km}$ for Barakar formation.

The mean depths of causative sources along the profile $\mathrm{EE}^{\prime}$ (passes east of the Parbatpur and Dubrajpur and west of Dungri, Kustore region, shown in Fig. 2) calculated from the CWT (Fig. 9a) and Daubechies' wavelet (Fig. 9b) vary from 1.8 to $2.8 \mathrm{~km}$. There is a gentle slope of the basin on the northern side, uplift of the basement in the southern part and steep slope close to the southern boundary fault, clearly indicated in this profile.

Magnetic field inclination, declination and azimuth angle (clockwise from true north) of this profile are $36.39,-0.12$ and $268.556^{\circ}$ respectively. The depth of the basement near the top pole is estimated to be about $1.5-1.6 \mathrm{~km}$ from the 

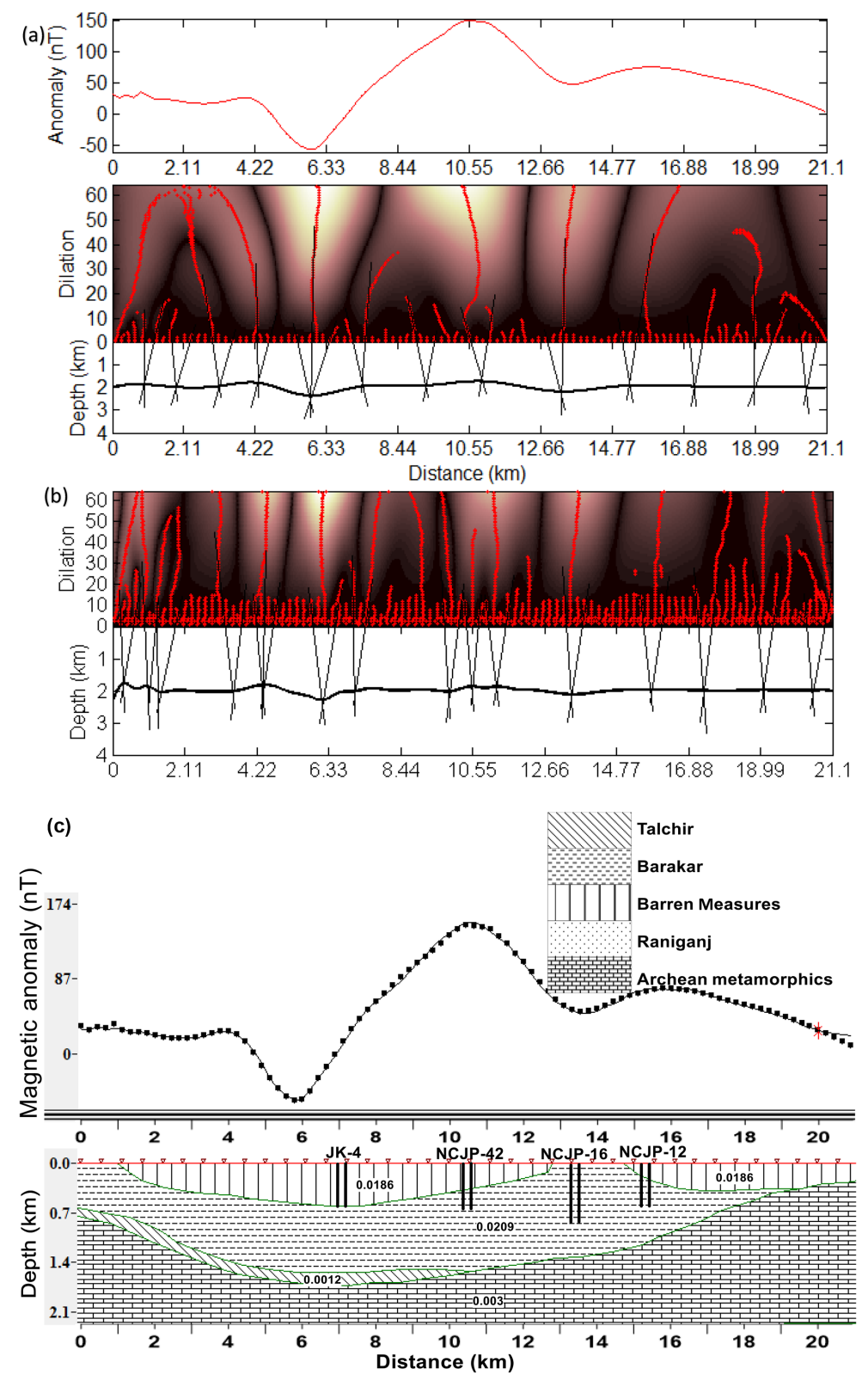

Figure 9. (a) Magnetic anomaly across the profile EE' (drawn in Fig. 2) and depth estimation by continuous wavelet transform. (b) Depth estimation by Daubechies' wavelet. (c) Geological section of the profile $\mathrm{EE}^{\prime}$ along with boreholes and magnetic susceptibility (shown in Table 2) of related formation.

surface. The anomaly high of about $149 \mathrm{nT}$ at the middle of the profile could be ascribed to the presence of basic or ultrabasic body which was a source for sills and basic dykes which intruded into the basin during Precambrian age. The south end of the underlying source is found to be at a depth of about $0.4 \mathrm{~km}$ and the north end at $0.7 \mathrm{~km}$ below the surface (Fig. 9c). The eastern margin shows the impact of the occurrence of some faults and extension of metamorphic runs under the sediments up to a distance of about $1.12 \mathrm{~km}$.

Geological sections along this profile are also deduced from the gravity data, borehole information and available ge- ological information. Individual thickness of each formation is also deduced with the help of boreholes JK-4, NCJP-42, NCJP-16 and NCJP-12, which are located southwest of Kustore, west of Nunikdih, west of Dungri and south of Dungri respectively. Maximum thickness is about $0.45 \mathrm{~km}$ for Barren Measures, $1.5 \mathrm{~km}$ for Talchir and $1.4 \mathrm{~km}$ for Barakar formation.

The mean depth of causative sources along the profile $\mathrm{FF}^{\prime}$ (passes east of the Jharia, Dhanbad and west of the Makunda and Pathardih regions, shown in Fig. 2) calculated from the CWT (Fig. 10a) and Daubechies' wavelet method (Fig. 10b) 

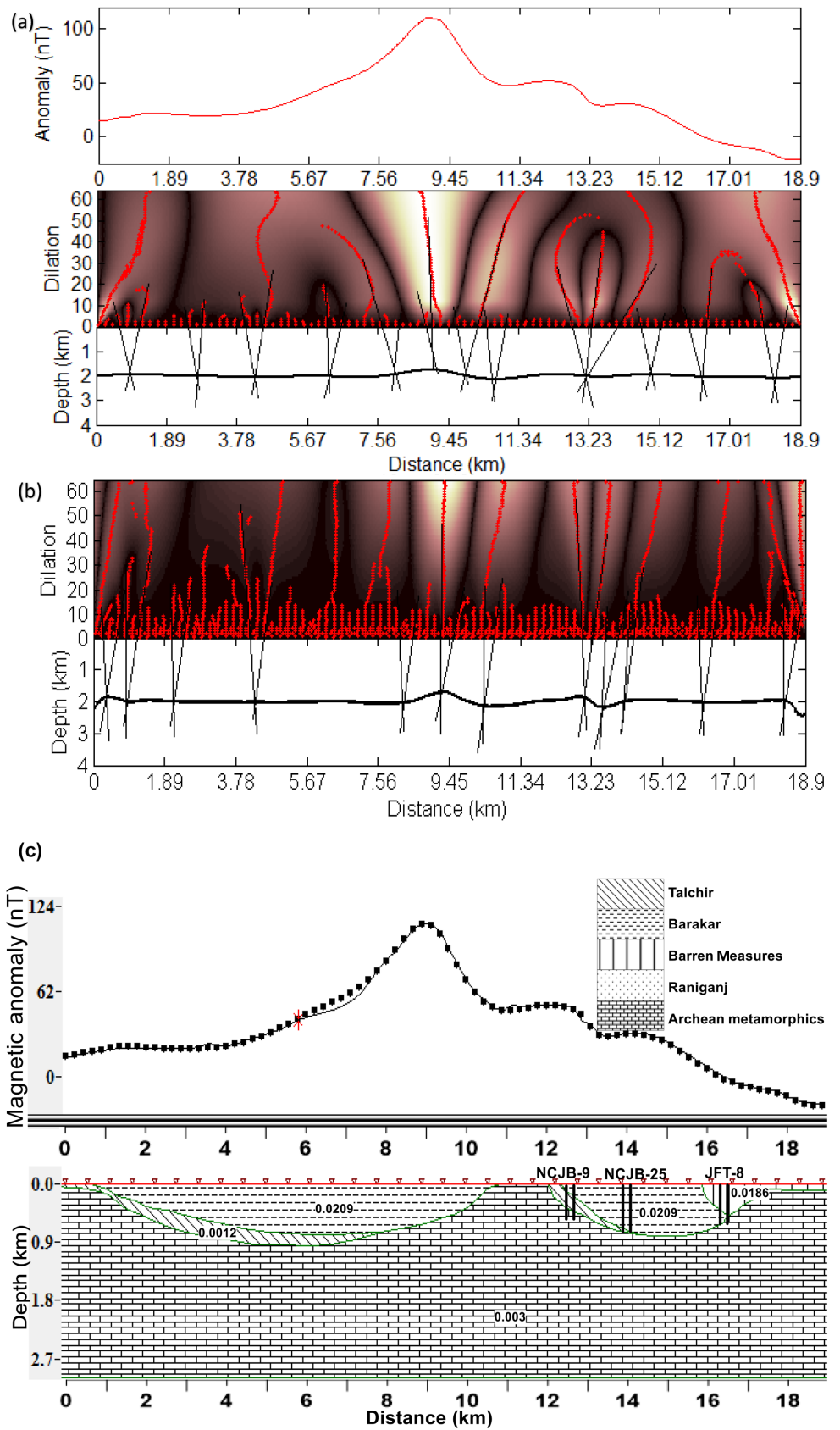

Figure 10. (a) Magnetic anomaly across the profile $\mathrm{FF}^{\prime}$ (drawn in Fig. 2) and depth estimation by continuous wavelet transform. (b) Depth estimation by Daubechies' wavelet. (c) Geological section of the profile $\mathrm{FF}^{\prime}$ along with boreholes and magnetic susceptibility (shown in Table 2) of related formation.

varies from 1 to $2.5 \mathrm{~km}$. Also, magnetic anomaly suggests that this area is geologically highly disturbed and dips of the formations vary rapidly.

Magnetic field inclination, declination and azimuth angle of this profile are $36.33,-0.13$ and $268.584^{\circ}$ respectively. Patherdih horst, which is a tongue of gneiss, penetrates the southeast corner of this region. There are strong faults that occur at both ends of the profile. Several interesting possibil- ities arise regarding the basic intrusives of dykes as well as schists which are normally magnetized. An anomaly of about $110 \mathrm{nT}$ at the middle of the profile is due to peridotite dykes and sills having a close association with Barren Measures and Barakar formation.

It is found that in this region of magnetic anomaly remanent magnetization of the body also appears to contribute to the magnetic anomaly. A number of sills and ultrabasic 

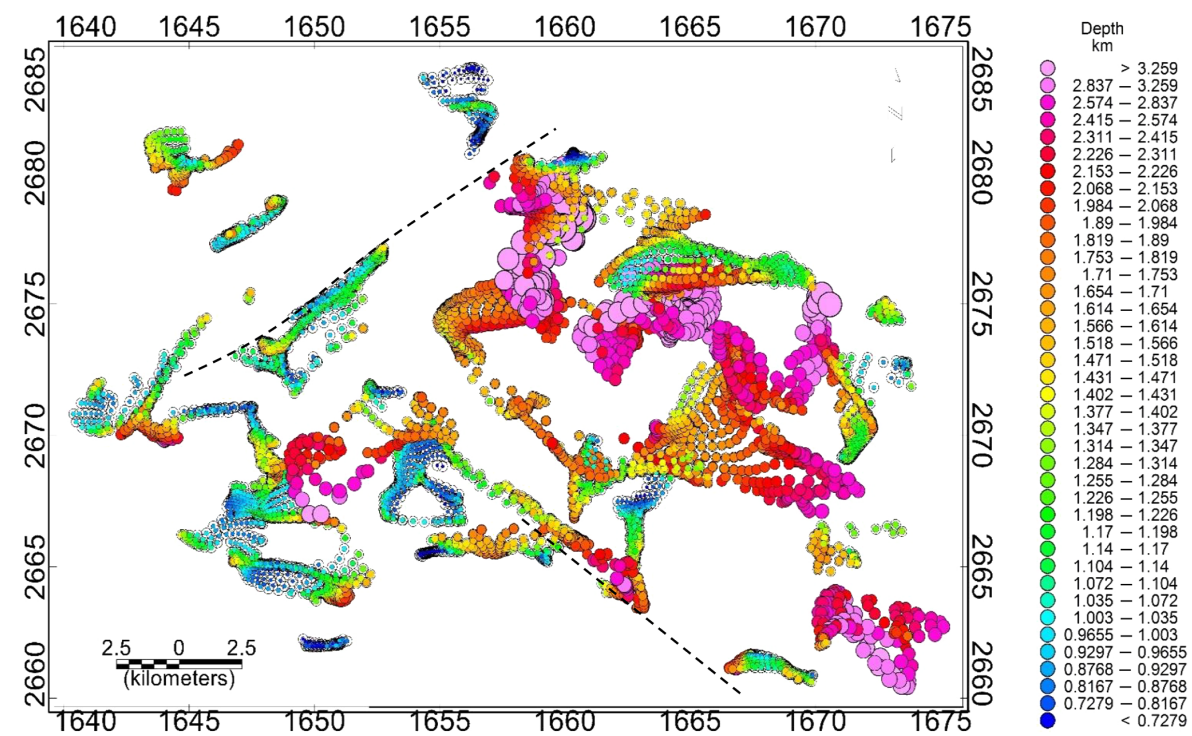

Figure 11. The depth estimates obtained from Euler deconvolution $(\mathrm{SI}=2)$ are plotted in UTM coordinates of the study region.

Table 1. Mean depth of causative sources calculated from magnetic anomaly by CWT, EDM and Daubechies' wavelet along the profiles drawn over Jharia coalfield and surrounding regions.

\begin{tabular}{|c|c|c|c|c|c|c|c|}
\hline \multirow[b]{2}{*}{$\begin{array}{l}\text { Names of } \\
\text { Profiles }\end{array}$} & \multicolumn{7}{|c|}{ Distance and depth (km) } \\
\hline & $\begin{array}{r}\text { Depth at } \\
3 \mathrm{~km} \text { from } \\
\text { the left }(\mathrm{km})\end{array}$ & $\begin{array}{r}\text { Depth at } \\
6 \mathrm{~km} \text { from } \\
\text { the left }(\mathrm{km})\end{array}$ & $\begin{array}{r}\text { Depth at } \\
9 \mathrm{~km} \text { from } \\
\text { the left }(\mathrm{km})\end{array}$ & $\begin{array}{l}\text { Depth at } \\
12 \mathrm{~km} \text { from } \\
\text { the left }(\mathrm{km})\end{array}$ & $\begin{array}{l}\text { Depth at } \\
15 \mathrm{~km} \text { from } \\
\text { the left }(\mathrm{km})\end{array}$ & $\begin{array}{l}\text { Depth at } \\
18 \mathrm{~km} \text { from } \\
\text { the left }(\mathrm{km})\end{array}$ & $\begin{array}{l}\text { Depth at } \\
21 \mathrm{~km} \text { from } \\
\text { the left }(\mathrm{km})\end{array}$ \\
\hline $\mathrm{AA}^{\prime}$ & 0.3 & 0.4 & 0.38 & 0.37 & 0.39 & - & - \\
\hline $\mathrm{BB}^{\prime}$ & 2 & 2.4 & 2.2 & 2.5 & 1.8 & - & - \\
\hline $\mathrm{CC}^{\prime}$ & 1.6 & 1.7 & 1.2 & 1.9 & 2 & - & - \\
\hline $\mathrm{DD}^{\prime}$ & 2.2 & 2.8 & 1.7 & 1.8 & 2.3 & - & - \\
\hline $\mathrm{EE}^{\prime}$ & 1.8 & 2.8 & 1.8 & 2 & 1.7 & 1.9 & 2.1 \\
\hline $\mathrm{FF}^{\prime}$ & 2.1 & 2.2 & 1 & 1.7 & 1.8 & - & - \\
\hline
\end{tabular}

dykes (mica peridotites) are found to be intrusive into the sediments. Geology over this profile could be ascribed to the presence of a basic or ultrabasic body which was the main source for the sills and basic dykes that intruded (Fig. 10c) into the basin during Gondwana times (Verma et al., 1973).

Geological strata along this profile are highly disturbed. Therefore, dips of the formations vary abruptly. The thickness of the formations is extrapolated from gravity data, boreholes NCJB-9, NCJB-25 and JFT-8 information as well as geological information. Boreholes NCJB-9, NCJB-25 and JFT- 8 are located west of Chhatabad, west of Patherdih and west of Bhojudih respectively. Borehole JFT- 8 has the cross contact between Barren Measures and Barakar formation and it touches the metamorphics about $0.4 \mathrm{~km}$ west of Bhojudih. The depth of the individual formations is approximately equal to the depth obtained from interpretation of gravity data (Singh and Singh, 2015).
The interpretation of magnetic anomaly over Jharia coalfield has been compared with some information from interpretation of gravity data (Verma and Ghosh, 1974). The mean depth of the causative sources estimated by Euler deconvolution method (Fig. 11) ranges about 0.6 to $3.2 \mathrm{~km}$. The mean depth of the profiles has been shown in the Table 1 .

Results from the total magnetic field of Jharia coalfield (Fig. 2) show that magnetic field anomalies are predominant due to irregular undulations of Precambrian outcrops and faults. The magnetic data are sampled at roughly $50 \mathrm{~m}$ along the profile direction. To enhance the signal-to-noise ratio, a high cut filter was applied in the wavenumber domain and partial derivative in the vertical direction was obtained by extending the field grid before the calculation. The SI is supposed to vary between 0 and 3 , covering all plausible geological bodies. The estimates of source location and depth are obtained by minimizing the error function using the nonlinear optimization technique of Coleman and Li (1996). 
Table 2. The following magnetic susceptibility used to prepare the geological sections. Susceptibility values are taken from the standard chart compiled by Clark and Emerson (1991) and Hunt et al. (1995).

\begin{tabular}{|c|c|c|}
\hline Formation & Litho-type & $\begin{array}{l}\text { Maximum volume } \\
\text { Magnetic susceptibility } \\
\text { (SI units) }\end{array}$ \\
\hline Raniganj & $\begin{array}{l}\text { Fine-grained feldspathic sandstones, } \\
\text { shales with coal seams }\end{array}$ & $\begin{array}{l}\text { Sandstone }=0.0209 \\
\text { Shale }=0.0186 \\
\text { Coal }=0.000025\end{array}$ \\
\hline $\begin{array}{l}\text { Barren } \\
\text { Measures }\end{array}$ & $\begin{array}{l}\text { Buff-colored sandstones, shales and } \\
\text { carbonaceous shales }\end{array}$ & $\begin{array}{l}\text { Sandstone }=0.0209 \\
\text { Shale }=0.0186\end{array}$ \\
\hline Barakar & $\begin{array}{l}\text { Buff-colored coarse and medium- } \\
\text { grained feldspathic sandstones, car- } \\
\text { bonaceous shales, fire clays and coal } \\
\text { seams }\end{array}$ & $\begin{array}{l}\text { Sandstone }=0.0209 \\
\text { Shale }=0.0186 \\
\text { Clay }=0.00025 \\
\text { Coal }=0.000025\end{array}$ \\
\hline Talchir & $\begin{array}{l}\text { Silt, carbonates } \\
\text { Greenish shale and fine-grained } \\
\text { sandstones }\end{array}$ & $\begin{array}{l}\text { Silt } / \text { carbonates }=0.0012 \\
\text { Shale }=0.0186 \\
\text { Sandstone }=0.0209\end{array}$ \\
\hline Metamorphics & $\begin{array}{l}\text { Granite gneisses, quartzites, mica } \\
\text { schists and amphibolites }\end{array}$ & $\begin{array}{l}\text { Granite }=0.05 \\
\text { Gneisses }=0.025 \\
\text { Quartzites }=0.0044 \\
\text { Mica schists }=0.003 \\
\text { Amphibolites }=0.00075\end{array}$ \\
\hline
\end{tabular}

Figure 11 shows two sets of fractures, predominantly oriented in the northeast and southeast at the northern and southern boundary respectively. The orientation of fractures sets are similar to that of the orientation obtained from regional magnetic interpretation (Verma et al., 1973). In the southern region, the depth of the Precambrian basement derived from the faults is less than that in the northern region. Furthermore, intense fracturing is detected at the center of the study area. In the western and southern regions, the basement depth is shallower compared to that of the eastern and northern region.

Profile analysis suggests that most of the basement lies below $700 \mathrm{~m}$, which is reasonable as calculated by wavelet transform method. The faults and depths obtained from the Euler deconvolution, CWT and Daubechies' wavelet are related to each other according to the results obtained from the regional magnetic interpretation.

\section{Conclusions}

The present analysis demonstrates the efficiency of continuous wavelet transform to delineate the locations of causative sources of potential field. Mean depth of the causative source along the profile $\mathrm{AA}^{\prime}$ from across Amdih and south of Telmuchu varies from 0.2 to $0.45 \mathrm{~km}$ and there is a fault near the northwestern part of the study region. The magnetic anomaly of about $77 \mathrm{nT}$ corresponds to the number of basic intrusive bodies belonging to the Satpura cycle. Mean depth of the pro- file $\mathrm{BB}^{\prime}$ calculated from the CWT varies from 1.3 to $2.5 \mathrm{~km}$. Central part of the basin shows abrupt changes in the magnetic anomaly. The key feature of this area is that most of the major portion is covered by the Raniganj and the Barakar formations. The estimated thickness of the sediment is about $2.3 \mathrm{~km}$ over the Raniganj formation. Mean depth of the profile $\mathrm{CC}^{\prime}$ calculated from the CWT and Euler deconvolution varies from 1 to $2 \mathrm{~km}$. A key feature of this profile is that sedimentary formations along the profile expose a strong indication that both boundaries have a slope towards the central part and that the southern boundary is more abrupt than the northern boundary. The mean depth of causative sources along the profile DD' calculated from the CWT and Euler deconvolution varies from 1 to $2.4 \mathrm{~km}$. Moreover, along this profile there is indication of fractious contact between the Barakar formation and Barren Measures, and the Barakar formation appears to pinch out close to the southern boundary fault. The mean depth of causative sources along the profile $\mathrm{EE}^{\prime}$ calculated from the CWT and Euler deconvolution varies from 1.8 to $2.8 \mathrm{~km}$. There is a gentle slope of the basin on the northern end, while uplift of the basement and a steep slope close to the southern boundary fault are clearly indicated in this profile. The mean depth of causative sources along profile $\mathrm{FF}^{\prime}$ calculated from the CWT and EDM varies from 1 to $2.5 \mathrm{~km}$. Also, magnetic anomalies suggest that the easternmost area is geologically highly disturbed and dips of the formations vary rapidly. 
Thus, the wavelet transform and Euler deconvolution methods provide sufficient and relevant information necessary to find the depth and location of the causative sources. The application of the CWT methods to the synthetic and field magnetic data across Jharia coalfield demonstrates that the technique is quick, easy to use and very efficient. Continuous wavelet transform and Euler deconvolution can give the mean depth of causative sources of magnetic field data, which can be interpreted qualitatively and quantitatively to determine the cause of anomaly. Also, these methods provide a way to infer the location of causative sources without any a priori information in a very short time and can be further used as a priori models in inversion to improve accuracies.

\section{Data availability}

The data used in this paper can be found in the online Supplement for this article.

\section{The Supplement related to this article is available online at doi:10.5194/gi-6-53-2017-supplement.}

Competing interests. The authors declare that they have no conflict of interest.

Acknowledgements. Authors are very thankful to D. C. Panigrahi, Director of IIT (ISM) Dhanbad, for providing the necessary infrastructure for this research to be successfully carried out. We are very grateful to Lev Eppelbaum, Associate Editor of this journal, who gave the initial reviews on earlier versions of the manuscript that greatly improved the final paper. We would also like to show our gratitude to Sanjay Prajapati, O. Menshov and an anonymous reviewer for their positive comments.

Edited by: L. Eppelbaum

Reviewed by: S. K. Prajapati, O. Menshov, and one anonymous referee

\section{References}

Ardestani, E. V.: Precise Edge detection of gravity anomalies by Tilt angle filters, J. Earth \& Space Phys., 36, 2, 11-19, 2010.

Barbosa, V. C. F., Silva, J. B. C., and Medeiros, W. E.: Stability analysis and improvement of structural index estimation in Euler deconvolution, Geophysics, 64, 48-60, 1999.

Blakely, R. J. and Simpson, R. W.: Approximating edges of source bodies from magnetic or gravity anomalies, Geophysics, 51, 1494-1498, 1986.

Bhattacharyya, B. P.: Tectono-metamorphic effect of granite and pegmatite emplacement in the Precambrian of Bihar Mica Belt. Proc. Symp. On Metallogeny of the Precambrian, Geological Society of India, Bangalore, India, 45-56, 1972.
Chamoli, A., Srivastava, R. P., and Dimri, V. P.: Source depth characterization of potential field data of Bay of Bengal by continuous wavelet transform, Indian J. Mar. Sci., 35, 195-204, 2006.

Clark, D. A. and Emerson, D. W.: Notes on rock magnetization characteristics in applied geophysical studies, Explor. Geophys., 22, 547-555, 1991.

Cooper, G. R. J.: A semi-automatic procedure for the interpretation of geophysical data, Explor. Geophys., 35, 180-185, 2004.

Cooper, G. R. J.: The semiautomatic interpretation of gravity profile data, Computat. Geosci., 37, 1102-1109, 2011.

Cooper, G. R. I. and Cowan, D. R.: Enhancing potential field data using filters based on the local phase, Computat. Geosci., 32, 1585-1591, 2006.

Cooper, G. R. J. and Cowan, D. R.: Edge enhancement of potential field data using normalized statistics, Geophysics, 73, H1-H4, 2008.

Coleman, T. F. and Li, Y.: An interior, trust region approach for nonlinear minimization subject to bounds, SIAM J. Optimiz., 6, 418-445, 1996.

Dewangan, P., Ramprasad, T., Ramana, M. V., Desa, M., and Shailaja, B.: Automatic interpretation of magnetic data using Euler deconvolution with nonlinear background, Pure Appl. Geophys., 164, 2359-2372, 2007.

FitzGerald, D., Reid A., and McInerney, P.: New discrimination techniques for Euler deconvolution, Computat. Geosci., 30, 461469, 2004.

Fox, C. S.: The Jharia Coal Field, Geological Survey of India, Memoir, 56, 1-255, 1930.

Gee, E. R.: The geology and coal resources of the Raniganj coalfield, Mem. Geol. Surv. India, 61, 1-343, 1932.

Gerovska, D. and Arauzo Bravo, M. J.: Automatic interpretation of magnetic data based on Euler deconvolution with unprescribed structural index, Computat. Geosci., 29, 949-960, 2003.

Goyal., P. and Tiwari, V. M.: Application of the continuous wavelet transform of gravity and magnetic data to estimate sub-basalt sediment thickness, Geophys. Prospect., 62, 148-157, 2014.

Gunn, P. J.: Linear transformations of gravity and magnetic fields, Geophys. Prospect., 23, 300-312, 1975.

Holschneider, M., Chambodut, A., and Mandea, M.: From global to regional analysis of the magnetic field on the sphere using wavelet frames, Phys. Earth Planet. In., 135, 107-124, 2003.

Hunt, C. P., Moskowitz, B. M., and Banerjee, S. K.: Magnetic properties of Rocks and Minerals, in: Rock Physics and Phase Relations - A hand book of Physical constants, AGU Reference shelf 3, edited by: Ahrens, T. J., 189-204, 1995.

Hsu, S. K.: Imaging magnetic sources using Euler's equation, Geophys. Prospect., 50, 15-25, 2002.

Hsu, S. K., Sibuet, J. C., and Shyu, C. T.: High resolution detection of geologic boundaries from potential-field anomalies: an enhanced analytic signal: technique, Geophysics, 61, 373-386, 1996.

Keating, P. B.: Weighted Euler deconvolution of gravity data, Geophysics, 63, 1595-1603, 1998.

Kopal., Z.: Numerical analysis, Chapman and Hall Ltd., London, UK, 551-553, 1961.

Melo, F. F., Barbosa, V. C. F., Uieda, L., Oliveira Jr., V. C., and Silva, J. B. C.: Estimating the nature and the horizontal and vertical positions of 3-D magnetic sources using Euler deconvolution, Geophysics, 78, J87-J98, 2013. 
Moreau, F., Gibert, D., Holschneider, M., and Saracco, G.: Wavelet analysis of potential fields, Inverse Probl., 13, 165-178, 1997.

Moreau, F., Gibert, D., Holschneider, M., and Saracco, G.: Identification of sources of potential fields with continuous wavelet transform: Basic theory, J. Geophys. Res., 104, 5003-5013, 1999.

Mushayandebvu, M. F., Van Driel, P., Reid, A. B., and Fairhead, J. D.: Magnetic source parameters of two dimensional structures using extended Euler deconvolution, Geophysics, 66, 814-823, 2001.

Mushayandebvu, M. F., Lesur, V., Reid, A. B., and Fairhead, J. D.: Grid Euler deconvolution with constraints for 2-D structures, Geophysics, 69, 489-496, 2004.

Perez, C., Wijns, C., and Kowalczyk, P.: Theta map: Edge detection in magnetic data, Geophysics, 70, L39-L43, 2005.

Ravat, D.: Analysis of the Euler method and its applicability in environmental investigations, J. Environ. Eng. Geoph., 1, 229-238, 1996.

Reid, A. B., Allsop, J. M., Granser, H., Millet, A. J., and Somerton, I. W.: Magnetic interpretation in three dimensions using Euler deconvolution, Geophysics, 55, 80-91, 1990.

Reid, A. B., Ebbing, J., and Webb, S. J.: Avoidable Euler Errors- the use and abuse of Euler deconvolution applied to potential field, Geophys. Prospect., 62, 1162-1168, 2014.

Sailhac, P., Gibert, D., and Boukerbout, H.: The theory of the continuous wavelet transform in the interpretation of potential fields: A review, Geophys. Prospect., 57, 517-525, 2009.

Salem, A., Williams, S., Fairhead, J. D., Ravat, D., and Smith, R.: Tilt-depth method: a simple depth estimation method using first order magnetic derivatives, The Leading Edge, 26/12, 15021505, 2007.

Silva, J. B. C. and Barbosa, V. C. F.: 3-D Euler deconvolution: Theoretical basis for automatically selecting good solutions, Geophysics, 68, 1962-1968, 2003.
Silva, J. B. C., Barbosa, V. C. F., and Medeiros, W. E.: Scattering, symmetry, and bias analysis of source position estimates in Euler deconvolution and its practical implications, Geophysics, 66, 1149-1156, 2001.

Singh, A. and Singh, U. K.: Wavelet analysis of residual gravity anomaly profiles: Modeling of Jharia coal basin, India, 86, 679686, 2015.

Stavrev, P. and Reid, A.: Degrees of homogeneity of potential fields and structural indices of Euler deconvolution, Geophysics, 72, L1-L12, 2007.

Stavrev, P. Y.: Euler deconvolution using di?erential similarity transformations of gravity or magnetic anomalies, Geophys. Prospect., 45, 207-246, 1997.

Thompson, D. T.: EULDPH: A new technique for making computer assisted depth estimates from magnetic data, Geophysics, 47, 31-37, 1982.

Verma, R. K. and Ghosh, D.: Gravity survey over Jharia coalfield, India. Geophys. Res. Bull., 12, 165-175, 1974.

Verma, R. K., Prasad, S. N., and Jha, B. P.: Magnetic Survey over Jharia Coal Field, Pure Appl. Geophys., 102, 124-133, 1973.

Verma, R. K., Majumdar, R., Ghosh, D., Ghosh, A., and Gupta, N. C.: Results of Gravity Survey over Raniganj Coalfield, India, Geophys. Prospect., 24, 19-30, 1976.

Verma, R. K., Bhuin, N. C., and Mukhopadhyay, M.: Geology, Structure and tectonics of Jharia Coal Field, India-A 3-D Model, Geoexploration, 17, 305-324, 1979.

Williams, S., Fairhead, J. D., and Flanagan, G.: Grid based Euler deconvolution: Completing the circle with 2-D constrained Euler, SEG Technical Program Expanded Abstracts, 22, 576-579, 2003.

Zhang, C., Mushayandebvu, M. F., Reid, A. B., Fairhead, J. D. and Odegard, M. E.: Euler deconvolution of gravity tensor gradient data, Geophysics, 65, 512-520, 2000. 